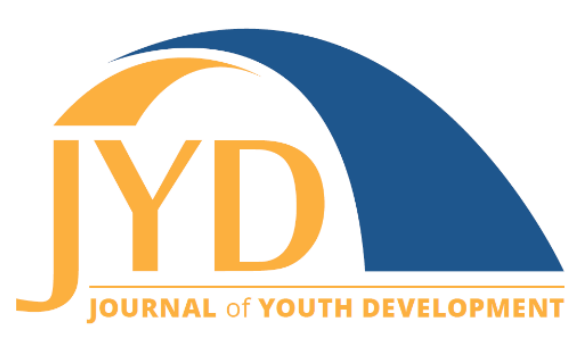

http://jyd.pitt.edu/ | Vol. 12 Issue 1 DOI 10.5195/jyd.2017.483 | ISSN 2325-4017 (online)

\title{
Building Blocks of Professionalism: Values, Principles, and Ethics in Youth Work
}

\author{
Deena M. Zubulake \\ YWCA St. Paul \\ dmzubulake@gmail.com
}

\begin{abstract}
This research began with questions about youth work professionalism and discovering the why and how behind youth work practice. This article explores relationship-centered values, principles of positive youth development, and ethics of professional youth work as the foundation for informing and guiding youth work professional practice.
\end{abstract}

\section{Introduction}

The professional values, principles, and ethics of the field of youth work are what inform best practice approaches and guide the day-to-day experiences between youth and youth workers. I researched the meaning and implications of youth work values, principles and ethics and I conducted formal interviews with five local professionals with direct youth work practice experience and managers of youth programs.

For the purpose of this article I will look at youth work practice, specifically among the youth services sector. Youth services, as differentiated from out-of-school time enrichment opportunities, is an arena in which services can include residential programming, therapeutic frameworks, individual counseling, and case management services. It is important to identify the role of youth services because it indicates the purpose of the relationship between youth and agency. Youth services and out-of-school time enrichment programs both offer young people a safe place, and opportunity to learn new things, build skills, and connect with community. Youth services target the most vulnerable and at-risk youth ensuring young people's basic needs of safety, food and shelter met first. Youth services often also include opportunities for family relationship building and/or independent living. There is a

\footnotetext{
(cc) EY New articles in this journal are licensed under a Creative Commons Attribution 4.0 License. This journal is published by the University Library System, University of Pittsburgh and is cosponsored by the University of Pittsburgh Press. The Journal of Youth Development is the official peer-reviewed publication of the National Association of Extension 4-H Agents and the National AfterSchool Association.
} 
concentrated effort in this part of the field for young people in transition to adulthood to stabilize, set their own goals, explore their strengths, and develop holistically.

The field of youth work has roots in both education and social work. The values, principles, and ethics from those fields have influenced the professional field of youth work. In exploring youth work-specific values, principles and ethics it is vital to begin with how youth workers define or understand their role in a young person's life. First and foremost, the relationship is of a professional nature. It must be acknowledged that youth workers are being paid to have a relationship with a young person and if they are volunteers or interns they both still represent the agency. The connection between the youth and youth worker is formed through a need or relationship with organization/agency first.

The role of power must be acknowledged and at times intentionally set aside to ensure best practice youth work. The youth worker has a twofold sense of power:

1. The power and privilege of adulthood: The intentionality of recognizing the power and privilege of adulthood can be difficult. Youth-adult partnership does not mean the adult youth worker is devalued. It does mean the adult youth worker is being purposeful and intentional in his/her role. Young people come into youth services or youth centered programming to meet a need. They come with established lived experiences, cultural and gendered frameworks, family values, and belief systems. It is the role of youth workers to uplift these inherent qualities, not impose their own or give direction on what youth need or should do.

2. Control of services, resources, and accessibility the young person is receiving: Youth workers have the power to make decisions that directly impact the lives of young people in programming. Youth workers must be careful to not hold or withhold resources based on youth behavior or other circumstances. Services, resources, and accessibility are inherent parts of being in programming.

\section{Relationship-Centered Values}

Think about it: To sit in a room with a young person-maybe you have met this young person before, maybe not. To share a space that has been purposefully and intentionally entered into. To sit silently in quiet and stillness, leaving room for the young person to decide when it is time to speak, to decide where to begin, to decide the words to choose. The story (and there is never just one) may be told all at once-maybe even without a breath-or it may be told slowly and carefully over time. It is a privilege to be in that kind of space with a young 
person. Once this relationship-oriented kind of interaction begins, it is vital, that the youth worker hears, sees and feels what the youth is giving. Through our values, we begin to truly believe in young people.

Relationship-centered philosophy or approach is a fundamental value to youth work practice. The values of acceptance, partnership, and believing in the worth of young people are critical to building connection between young people and youth worker. The value of being relationship-centered impacts how youth are seen, treated, and talked about. It is not uncommon for adults' or societies' general attitudes toward young people to be negative, for young people to be seen as irresponsible, defiant, and often as individuals or groups to fear. It is the youth workers' framework to view youth differently and challenge these biases. Youth workers create a safe place by seeing young people through a lens that reflects their strengths; respects their ideas, stories, relationships and lived experiences; and views them as individuals who have something to offer. The value of seeing young people through this positive and strength-based lens creates true youth-adult partnerships, avoids powerstruggles, and gives young people the opportunity to be equitable contributors. Mark Krueger (2005) described four themes of youth work practice that reflect these values in how a youth worker should approach youth work:

- Presence: The ability to bring self (youth worker) to the moment. "I am here; I will go with you."

- Rhythmic Interaction: The human connection; movement toward resolution, moment of connection, discovery, empowerment.

- Meaning Making: An understanding of youth contextual reality; construct and deconstruct; moving-talking-and being together.

- Atmosphere: The tone, mood, space, and place.

This lens challenges youth workers to be conscious of how young people are talked about, especially when they are not in the room. The youth worker becomes the advocate and ensures the young person's voice, ideas, lived experience is being valued.

Throughout the interviews I conducted with youth work professionals and reflecting on my own career, the values that continue to be at the forefront of the work are:

- Believe in young people.

- Consider diversity. 
- Be consistent.

- Find ways to stay creative.

- Utilize a strength-based philosophy.

These critical ideas are the foundation of youth work values. Youth programs want to create a sense of community and connection in a way youth may not experience in other circumstances. Being relationship-centered is building trust. Believing in the value of young people sets an intention of worth and trust. Considering diversity is a cornerstone of holistic work. Welcoming an individual's complexities and intersectionalities gives room for young people to be who they need to be in that moment. Walking with young people through the evolution of identity is one of the beautiful experiences of this work. Creativity and relentless curiosity are the driving forces behind opportunity, accessibility, and authentic relationship building. Strength-based philosophy language and frameworks may evolve and change, yet the premise that young people are more than their circumstances, behavior, and perceptions is critical to how young people are valued.

\section{Positive Youth Development Principles}

Think about it: For a young person who has known violence, fear, and trauma this is real life. Not a news story or the next blockbuster movie. Living for survival is complicated. For some, running away from home seems easier than the inevitable fight. For others the doors are locked and they are not wanted at home. It takes a significant amount of courage for a young person to walk through the door of an agency, but when they arrive, they are welcomed without judgment. There are caring adults and peers with similar stories. There is safety. There is listening. There are conversations that explore where they have been, what's important to them, and where they want to go. Every interaction is intentional and purposeful to provide a safe and affirming experience. This young person is given the freedom to explore, wrestle with new ideas, and encounter new experiences. These are the seeds of hope and change.

Positive Youth Development is best practice youth work. Positive youth development begins with the value of relationship-centered youth-adult partnership and identifies core principles all youth need to thrive. In the Positive Youth Development Toolkit, Ansell et al. (2008) describe the four principal areas of concentration: belonging, mastery, independence and generosity: 
- Belonging is a result of having "a positive relationship with a trustworthy adult, being in an inclusive program and having a safe environment" (p. 13).

- Mastery includes "developing knowledge, skills, abilities, and attitudes then being given the opportunity to demonstrate them in a proficient manner" (p. 14).

- Independence is about "self-reliance, self-determination, and capturing one's own hope and optimism and believing that one has some impact or control over life's events" (p.15).

- Generosity means "providing youth with opportunity to participate in something larger than themselves" (p. 15).

Positive Youth Development principles are utilized across youth programming models. Creating a sense of belonging for youth ensures both a safe environment and building a relationship with a caring adult. Safety can look different depending on the setting, yet it must include both a safe physical space and safe dynamics between youth participants. An environment that affirms young people in their identity, builds community and connection, and provides a consistent youth worker relationship is belonging. Providing youth access and resources to learn new things is mastery. Learning academics through informal education, building life skills to navigate young adulthood, and expanding a young person's world view contribute to the principle of mastery. Independence is an opportunity for youth to identify the things that are most important to them, discover possibilities, and make decisions. Youth workers provide young people with relationship and opportunities to process those decisions and receive support as youth pursue goals, hopes, and dreams. Youth work and youth participating in programming is not done in isolation. Bringing youth together through community involvement, volunteering, team work, and learning about others is how many youth programs connect young people to one another and to ideas greater than themselves.

These critical principles have been in the making for over 40 years, forming a solid cornerstone on which to build a common understanding of youth work principles. In 1973, Gisela Konopka worked with colleagues to develop a framework of basic need requirements for work with adolescents. Konopka's, Requirements for Healthy Development of Adolescent Youth has influenced and shaped the positive youth development approach. These basic needs are: feel a sense of safety; experience active participation; develop self-worth through contribution; experiment to discover self and gain independence; develop significant quality relationships particularly with at least one caring adult; discuss conflicting values to develop 
own personal values; feel pride of competence and mastery; and expand capacity to enjoy life and know success is possible.

\section{Ethics of Youth Work}

Think about it: When there is discussion about ethics it is advised to ask oneself questions: "Whose needs are being met by the interaction?" or "What purpose is this specific course of action, conversation, or activity serving?" In an age of social media there is greater and more constant exposure to images, photos, intimate thoughts or expression that is immediately public with worldwide access. As an individual, there is no ethical issue. People can choose how they publicly present their person, personality, ideas and experiences. There becomes an ethical dilemma, however, when a youth-serving organization puts out into the world, for the purpose and gain of the organization (fundraising), the image, identifiable story, idea, or experience of a young person who is currently receiving services. This action serves the needs and interests of the organization - the justifications being that young people benefit from fundraising and public awareness because it keeps the doors of the organization open and that young people are "empowered" by sharing their image or identifiable story, idea or experiences. It is our responsibility as a community of youth service providers to grapple with the ethics of using young people's intimate life stories for fundraising purposes. We are dealing with real lives, and using these stories for the benefit of the organizations has unseen consequences on the healing, personal growth development and self-image of our young people over time.

Currently, youth work in the United States does not have a code of ethical conduct. The profession relies more on a philosophical approach for dealing with human conduct or the right/wrongness of behavior. In her chapter Ethics and Values in Work with Young People, Banks (2009) suggests two questions to ask when considering an ethical situation. 1. "How should we act?" and 2. "What sorts of people we should be?" (p. 48). Both are vital questions, yet in exploring professional ethics the "how should we act?" is what usually develops into a professional code of conduct.

One youth worker I interviewed stated, "Ethics is common sense," and yet ethical dilemmas are a constant area of conversation, consultation, and training among youth-serving agencies. An interviewee who manages professional youth workers was very clear when she stated, "Most mistakes in youth work are in ethics or boundaries." 
The philosophical conduct behind youth work ethics has been influenced by the fields of social work and psychology. The codes of conduct we have adopted from in these fields include: boundaries between the youth workers and young people; safety and well-being of young people; respect or valuing the young person as an individual with experiences, ideas and relationships that are meaningful; and accountability for the adults in young people's lives.

\section{Professionalization}

Most youth workers begin their careers as an entry level employee, some with college education and some with life experience. Youth workers are not "youth workers" on the first day. They develop professional skills primarily through the agency in which they work, through teaching, training and mentoring from supervisors and peers. Throughout the professional learning process, consultation and debriefing are vital. These tools provide opportunities to process challenging situations, explore bias, discover opportunities to try different approaches or skills, and ensure ethical conduct. This experience can be challenging and leads the youth worker to self-reflection. Self-reflection is an essential learning model in youth work. Learning to understand what we bring to this work influences the way in which we can be purposeful and intentional in how we do this work.

Youth work is at the center of people work. It is influenced by the professional worlds of social work, education, justice, and even medicine as a source of how to professionalize the field. Maybe even more importantly, those professions are influenced by youth work. Many young adults move from their first jobs as youth workers into other people-centered career fields. When they make that transition, they bring with them the values, principles and ethics learned from youth work practice as a foundation to their professional identity. "Good child and youth care isn't brain surgery - it's much more difficult. No educational courses, training programs or text books can give you what you need in order to be with, understand and guide a young person through the fear, pain, chaos and anger once these demons are at work. We are not dealing with theory and strategic intervention here. Being in relationship means that we have what it takes to remain open and responsive in conditions where most mortals - and professionals - quickly distance themselves, become 'objective' and look for the external 'fix' " (Fewster, 2004, p.3).

A professional continuum of care for our young people includes: prevention-to-crisis interventions; shelter, housing; life skills; leadership; connections to community, education and employment. The field of youth work sets a professional standard for guidelines of 
interaction, youth worker professional development and impact. Youth work professionals engage young people in authentic relationships affirm and create space for youth to give voice to lived experience and developing identities, and work alongside young people empowering them to pursue possibilities.

Youth work-based programs provide a safe place to tell a story or connect with an adult. They provide opportunities that expose young people to new ideas and new experiences, and a chance for young people to determine their own path. Youth programs create a community context where young people can find ways to participate, lead, and give of themselves.

As youth workers we must hold one another to a standard that respects a young person's voice beyond setting goals or having a youth advisory panel. Honoring youth voice requires youth workers to pause and check their own bias, and to restrain the adult need to control, or enforce a rule. It requires youth workers to be purposeful and intentional as they welcome young people into organizations. We, as providers of services to young people, can ask ourselves why and how are we doing this work. We must consult, debrief, challenge one another and support each other. There are vital questions to consider: how should we act and what kind of agencies do we want to be?

Youth work is not done in isolation. Youth work is a partnership among young people, caring adults, and community support. Youth work is rooted in hopefulness and possibility. It is the responsibility of youth work-oriented organizations to ensure high quality programming and to invest in youth work professionals with training, supervision support, and/or mentoring. Creating opportunities for young people to thrive requires collective investment. Professional youth work practice is critical to establishing credibility, safety and security, and quality experiences for youth and families. The foundation of youth work professionalism is in understanding values, principles, and ethics guiding and informing the field of youth development.

\section{References}

Ansell, D., Burns, P., Carpenter-Williams, J., Cassidy, T., Finck, C., Peck Jr., R., ... Zanghi, M. (2008). Positive youth development toolkit: Engaging youth in program development, design, implementation, and service delivery. Tulsa, OK: National Resource Center for Youth Services. 
Journal of Youth Development | http://jyd.pitt.edu/ | Vol. 12 Issue 1 DOI 10.5195/jyd.2017.483 Building Blocks of Professionalism: Values

Banks, S. (2009). Ethics and values in work with young people. In J. Wood, \& J. Hine (Eds.), Work with Young People (pp. 48-59). London: Sage.

Fewster, G. (2004). Editorial. Relational Child \& Youth Care Practice, 173), 3-4.

Konopka, G. (1973). Requirements for healthy development of adolescent youth. Adolescence, 8(31), 1-26.

Krueger, M. (2005). Four themes in youth work practice. Journal of Community Psychology, $33(1), 21-29$. 